\title{
Differential Effects of Methyl-4-Phenylpyridinium Ion, Rotenone, and Paraquat on Differentiated SH-SY5Y Cells
}

\author{
João Barbosa Martins, ${ }^{1}$ Maria de Lourdes Bastos, ${ }^{1}$ \\ Félix Carvalho, ${ }^{1}$ and João Paulo Capela ${ }^{1,2}$ \\ ${ }^{1}$ REQUIMTE (Rede de Química e Tecnologia), Laboratório de Toxicologia, Departamento de Ciências Biológicas, \\ Faculdade de Farmácia, Universidade do Porto, Rua de Jorge Viterbo Ferreira 228, 4050-313 Porto, Portugal \\ ${ }^{2}$ Faculty of Health Sciences, University Fernando Pessoa, Rua Carlos da Maia 296, 4200-150 Porto, Portugal
}

Correspondence should be addressed to João Barbosa Martins; joao_b_martins@hotmail.com and João Paulo Capela; joaocapela@ff.up.pt

Received 15 November 2012; Revised 28 January 2013; Accepted 28 January 2013

Academic Editor: Lucio Guido Costa

Copyright (C) 2013 João Barbosa Martins et al. This is an open access article distributed under the Creative Commons Attribution License, which permits unrestricted use, distribution, and reproduction in any medium, provided the original work is properly cited.

\begin{abstract}
Paraquat (PQ), a cationic nonselective bipyridyl herbicide, has been used as neurotoxicant to modulate Parkinson's disease in laboratory settings. Other compounds like rotenone (ROT), a pesticide, and 1-methyl-4-phenylpyridinium ion $\left(\mathrm{MPP}^{+}\right)$have been widely used as neurotoxicants. We compared the toxicity of these three neurotoxicants using differentiated dopaminergic SHSY5Y human cells, aiming to elucidate their differential effects. PQ-induced neurotoxicity was shown to be concentration and time dependent, being mitochondrial dysfunction followed by neuronal death. On the other hand, cells exposure to $\mathrm{MPP}^{+}$induced mitochondrial dysfunction, but not cellular lyses. Meanwhile, ROT promoted both mitochondrial dysfunction and neuronal death, revealing a biphasic pattern. To further elucidate PQ neurotoxic mechanism, several protective agents were used. SH-SY5Y cells pretreatment with tiron (TIR) and 2-hydroxybenzoic acid sodium salt (NaSAL), both antioxidants, and $N_{\omega}$-nitro-L-arginine methyl ester hydrochloride (L-NAME), a nitric oxide synthase inhibitor, partially protected against PQ-induced cell injury. Additionally, 1-(2-[bis(4-fluorophenyl)methoxy]ethyl)-4-(3-phenyl-propyl)piperazine (GBR 12909), a dopamine transporter inhibitor, and cycloheximide (CHX), a protein synthesis inhibitor, also partially protected against PQ-induced cell injury. In conclusion, we demonstrated that PQ, MPP ${ }^{+}$, and ROT exerted differential toxic effects on dopaminergic cells. PQ neurotoxicity occurred through exacerbated oxidative stress, with involvement of uptake through the dopamine transporter and protein synthesis.
\end{abstract}

\section{Introduction}

Parkinson's disease (PD) is considered the second most common neurodegenerative disorder worldwide, affecting 0.5 to $1 \%$ of the population aged between 65 and 69 years and 1 to $3 \%$ of the population over 80 years [1]. PD develops from a loss of nigrostriatal neuromelanin-containing dopaminergic neurons, whose cell bodies lay in the substantia nigra pars compacta ( $\mathrm{SNpc}$ ) [2]. This nigrostriatal pathway is essential for a normal motor function and movement control. PD is thought to have a multifactorial etiology, frequently including genetic and environmental factors $[2,3]$. Several neurotoxic chemicals to dopaminergic neurons leading to PD-like symptoms have been used to study this disease. The synthetic compounds 1-methyl-4phenyl-1,2,3,6-tetrahydropyridine (MPTP) and 1-methyl-4phenyl-4-propionoxy-piperidine (MPPP) were the first to be associated with PD symptoms, as described by Langston and Ballard [4]. MPTP enters the blood-brain barrier and is metabolized in glial cells by monoamine oxidases to 1methyl-4-phenyl-2,3-dihydropyridium $\left(\mathrm{MPDP}^{+}\right)$, which is subsequently oxidized to $\mathrm{MPP}^{+}$[5]. Next, $\mathrm{MPP}^{+}$enters the dopaminergic cell via dopamine transporter (DAT) [5], accumulates inside the mitochondria, and interferes with complex I of mitochondrial transport chain, inhibiting its activity [6]. This reduces ATP cellular stores, promoting reactive oxygen species (ROS) formation and consequentially leading to neuronal death [5]. Another substance known to promote 
Parkinsonism is the organic pesticide rotenone (ROT), which is used worldwide as an insecticide and to eliminate nuisance fish populations, in lakes and reservoirs [3]. It is used to study PD given its ability to cross biological membranes, not depending on transporters, inhibiting mitochondrial complex I [7] which increases the rate of mitochondrial ROS release, leading to cell apoptosis $[3,8]$. Despite their use as PD models, neither ROT nor $\mathrm{MPP}^{+}$were correlated with the sporadic occurrence of PD [8]. These two neurotoxicants are currently used to study PD by means of in vivo and in vitro approaches; however, none of these substances reproduces completely all the clinical features observed in $\operatorname{PD}[8,9]$.

The lack of adequate cellular and/or animal models of PD has prompted the screening of many putative neurotoxic compounds. Paraquat (PQ) has received recently a wide attention as a possible inducer of PD. In fact, occupational exposure, especially in farming, has been associated with Parkinsonism [10] and also, it was demonstrated that patients who died from PQ poisoning had severe brain damage [11]. This was corroborated by studies, in animals, where besides the affection of the lung which is the main target organ for PQ toxicity, it was also demonstrated to be toxic to dopaminergic neurons $[12,13]$. Several mechanisms have been postulated for PQ-induced neurotoxicity, including increase in ROS formation, excitotoxicity, and mitochondrial complex I inhibition [14-16]. Nonetheless, the mechanisms by which PQ promotes neurotoxicity still remain to be fully elucidated.

The present work aimed to study the differences in terms of dopaminergic neurotoxic profile among PQ, ROT, and $\mathrm{MPP}^{+}$in a cell culture model with a dopaminergic phenotype. Also, we intended to provide further insights into the mechanism of PQ-induced neurotoxicity. For that purpose, human dopaminergic SH-SY5Y-differentiated cells were used.

\section{Materials and Methods}

2.1. Materials. The reagents for cell culture were obtained from Gibco (Invitrogen, Paisley, UK): Dulbecco's Modified Eagle Medium (D-MEM), nonessential amino acids (NEAA), phosphate-buffered saline (PBS), trypsin/EDTA, and penicillin/streptomycin. 48 Multiwell plates and $35 \mathrm{~mm}$ plates were obtained from Corning Costar (Corning, NY, USA). $25 \mathrm{~cm}^{3}$ flasks were obtained from TPP (Trasadingen, Switzerland); Fuchs-Rosenthal Counting Chamber was obtained from Carl-Rhode (Germany). Other reagents, namely, trypan blue solution $(0.4 \%)$, dimethyl sulfoxide (DMSO), retinoic acid (RA), 12-O-tetradecanoyl-phorbol-13-acetate (TPA), 3-[4,5-dimethylthiazol]-2,5-diphenyltetrazolium (MTT), sodium dodecyl sulfate (SDS), enzyme-standard for kinetic lactate dehydrogenase (LDH)-assay, $\beta$-nicotinamide adenine dinucleotide reduced form $(\beta-\mathrm{NADH}), 1,1^{\prime}$-dimethyl-4,4' -bipyridinium dichloride (Paraquat or PQ), rotenone (ROT), 1-methyl-4-phenyl-pyridinium ion $\left(\mathrm{MPP}^{+}\right)$, $N$-acetylcysteine (NAC), tiron (TIR), 1-(2-[bis(4-fluorophenyl)methoxy]ethyl)-4-(3-phenyl-propyl)piperazine (GBR 12909), cycloheximide (CHX), 2-hydroxybenzoic acid sodium salt (NaSAL), and $N_{\omega}$-nitro-L-arginine methyl ester hydrochloride (L-NAME), were obtained from SigmaAldrich (St Louis, MO, USA).

2.2. Cell Line and Culture Conditions. Human neuroblastoma SH-SY5Y cells (ATCC, Manassas, VA, USA) were used. Through differentiation (see protocol below), SH-SY5Y cells are able to express dopaminergic markers, as well as tyrosine hydroxylase, DAT, and higher ability to accumulate dopamine and exhibit extended neurites $[17,18]$. In this way, the cells are no longer immature, mitosis rate is reduced, and also differentiation agents can mimic factors secreted by astrocytes in a the natural brain environment. In other words, differentiation can provide a cellular model more similar to dopaminergic neurons $[17,18]$. The cells were grown in DMEM containing $4.5 \mathrm{mg} / \mathrm{L} \mathrm{D}$-glucose, $2 \mathrm{mM}$ L-glutamine, $110 \mathrm{mg} / \mathrm{L}$ sodium pyruvate, phenol red supplemented with $10 \%$ fetal bovine serum, $100 \mu \mathrm{g} / \mathrm{mL}$ penicillin, $100 \mu \mathrm{g} / \mathrm{mL}$ streptomycin, and 1\% NEAA, under an atmosphere of $5 \%$ $\mathrm{CO}_{2} / 95 \%$ air at $37^{\circ} \mathrm{C}$.

2.3. Experimental Protocol. Stock cultures of SH-SY5Y cells (passages 20 to 45) were maintained in $25 \mathrm{~cm}^{3}$ flasks and grown until confluence (70-80\% confluence). Cells were washed with PBS, trypsinized (trypsin/EDTA 0.05/ $0.02 \% \mathrm{w} / \mathrm{v}$ ), counted by trypan blue exclusion, using a FuchsRosenthal counting chamber, and subcultured at the density of 25000 cells $/ \mathrm{cm}^{2}$ in 48 -well culture plates. SH-SY5Y cells were differentiated, in order to enhance the dopaminergic phenotype, by the addition of $10 \mu \mathrm{M}$ RA to the medium for 3 days, after which the medium was added with 70 nM TPA and kept for another 3 days, in accordance with previous works $[17,18]$. Finally, the medium was removed and replaced with $250 \mu \mathrm{L}$ fresh medium alone or with the drugs: PQ $(100,500$, and $1000 \mu \mathrm{M}), \mathrm{MPP}^{+}(100,500$, and $1000 \mu \mathrm{M})$ and ROT (1, 10 , and $100 \mu \mathrm{M})$. Concentrations of the neurotoxicants were selected in accordance with previous studies [19-24]. The cells were exposed to the drugs for different time periods $(24,48$, and $72 \mathrm{~h}$ ). ROT was initially prepared in DMSO and then diluted in medium in order to obtain a final concentration of $0.1 \%$ of DMSO in the culture medium, which was not toxic to cells. To avoid variations among cell cultures that could interfere in the toxicity outcome, results for the concentrationtoxicity curves of the 3 toxins were obtained from several cell cultures resulting from different passages and were seeded in different days. Cell culture procedures and validation of the differentiation protocol of SH-SY5Y cells were previously published by our group [18]. After selecting the concentration and time of exposure through screening experiments, the antioxidants NAC (1 mM) [25], and TIR $(100 \mu \mathrm{M}$ and $1 \mathrm{mM})$ [26], the specific DAT inhibitor GBR $12909(1 \mu \mathrm{M})$ [23], the protein synthesis inhibitor CHX (1.8 nM) [27], the radical scavenger $\mathrm{NaSAL}(100 \mu \mathrm{M}$ and $1 \mathrm{mM})$ [28], and the nonselective nitric oxide synthase (NOS) inhibitor L-NAME $(1 \mu \mathrm{M})$ [29] were added 30 minutes before exposure of cells to PQ. These concentrations of the pharmacological antagonists were selected according to the drug selectivity to the target 
and also taking into account previous cell culture studies mentioned above.

2.4. Life-Death Assays. Cell cultures were assessed morphologically by phase contrast microscopy at 3 different time points $(24,48$, and $72 \mathrm{~h})$. Cell damage was assessed quantitatively by the measurement of $\mathrm{LDH}$ release into the medium (as a measure of cell membrane integrity) using a kinetic measurement assay. Also, mitochondrial dysfunction was assessed by the measurement of MTT salt metabolism assay.

2.4.1. Lactate Dehydrogenase Kinetic Assay. The quantification of LDH activity was made by a colorimetric method, which is based on the reversible reduction of pyruvate to lactate in the presence of $\beta-\mathrm{NADH}$, as described by Capela et al., 2006. After exposure to drugs, two aliquots ( $50 \mu \mathrm{L}$ each) of the medium were removed, to which a previously prepared $0.15 \mathrm{mg} / \mathrm{mL} \beta$-NADH solution was added, at room temperature, in a 96-well microplate. Finally, pyruvate $22.7 \mathrm{mM}$ was added to start the reaction. $\mathrm{NADH}$ oxidation to $\mathrm{NAD}^{+}$was measured at $340 \mathrm{~nm}$, using a colorimetric 96-well plate reader (BioTek Instruments, VT, USA). The delta increase in LDH release into the medium was calculated by subtraction of the respective controls, which were untreated cells cultured alongside the treated cells. LDH values are expressed in units per liter $(\mathrm{U} / \mathrm{L})$, calculated based on a LDH standard solution activity of $500 \mathrm{U} / \mathrm{L}$ [29].

2.4.2. MTT Assay. This colorimetric assay relies on the ability of viable, but not dead cells to convert a soluble yellow tetrazolium dye, MTT, into an insoluble blue formazan product that can be measured at $550 \mathrm{~nm}$. Given the removal of $100 \mu \mathrm{L}$ of culture medium used for the LDH assay, each well was added $50 \mu \mathrm{L}$ fresh medium to obtain $200 \mu \mathrm{L}$ of cell medium per well, to which the MTT solution was added (final concentration of MTT $500 \mu \mathrm{g} / \mathrm{mL}$ ). Subsequently, cells were incubated at $36.5^{\circ} \mathrm{C}$ for 3 hours. The reaction was stopped by adding an equal volume of $10 \%$ SDS in $0.01 \mathrm{M}$ hydrochloric acid solution followed by an overnight incubation at $36.5^{\circ} \mathrm{C}$. Finally, formazan was detected at $550 \mathrm{~nm}$ using a colorimetric 96-well plate reader, as previously described [29]. The viability of untreated control cells was set to $100 \%$, and the effects resulting from toxicant exposure were expressed as the percentage of the respective controls.

2.5. Statistical Analysis. Results are presented as mean \pm S.E.M., from at least 3 different independent experiments. The means for concentration/time graphics were compared using the two-way ANOVA, followed by the Bonferroni post hoc test, once a significant $P$ had been obtained. The means for the tested neuroprotectors were compared using the one-way ANOVA, followed by Student-Newman-Keuls post hoc test, once a significant $P$ had been obtained. Details of the statistical analyses are described in each figure legend. Significance was accepted when $P$ was less than 0.05 .

\section{Results}

3.1. Paraquat Was Toxic to SH-SY5Y Cells in a Concentrationand Time-Dependent Manner. The exposure of differentiated SH-SY5Y cells to PQ $(100 \mu \mathrm{M}, 500 \mu \mathrm{M}$ and $1000 \mu \mathrm{M})$ for $24 \mathrm{~h}$, did not result in elevation of $\mathrm{LDH}$ release at any concentration tested (data not shown). However, at $48 \mathrm{~h}$ there was a significant LDH release with $500 \mu \mathrm{M}$, which was even more marked with $1000 \mu \mathrm{M}$ exposure. As expected, LDH release into the medium was more pronounced at $72 \mathrm{~h}$, for 500 and $1000 \mu \mathrm{M}$. Thus, the loss of cellular viability occurred in a concentration- and time-dependent manner (Figure 1(a)). Mitochondrial dysfunction was assayed by the MTT assay. In contrast to cellular death evaluated by the $\mathrm{LDH}$ release, mitochondrial dysfunction was already visible at the $24 \mathrm{~h}$ time-point for the $500 \mu \mathrm{M}$ and $1000 \mu \mathrm{M}$ concentrations. For the $100 \mu \mathrm{M}$ concentration, PQ decreased significantly MTT reduction at $48 \mathrm{~h}$ but especially at $72 \mathrm{~h}$. Therefore, it could be clearly observed that mitochondrial dysfunction also occurred in a concentration- and time-dependent manner (Figure 1(b)).

\section{2. $\mathrm{MPP}^{+}$-Induced Mitochondrial Dysfunction in SH-SY5Y} Cells. Following exposure of SH-SY5Y cells to $\mathrm{MPP}^{+}$ $(100 \mu \mathrm{M}, 500 \mu \mathrm{M}$, and $1000 \mu \mathrm{M})$, there was no increase in cell injury at any time-point or concentration tested, as assessed by the $\mathrm{LDH}$ release into the medium (data not shown). On the other hand, $\mathrm{MPP}^{+}$proved to induce mitochondrial dysfunction (Figure 2). In fact, there was significant mitochondrial dysfunction already after $24 \mathrm{~h}$ of exposure to $500 \mu \mathrm{M}$, and $1000 \mu \mathrm{M}$ concentrations. There was no apparent increase in the toxicity by extending the exposure period to $48 \mathrm{~h}$. However, at $72 \mathrm{~h}$ MTT metabolism decreased significantly for all concentrations tested, especially for $1000 \mu \mathrm{M}$. Only at this point the toxicity of $1000 \mu \mathrm{M}$ was significantly higher than $500 \mu \mathrm{M}$ (Figure 2). Thus, only longer periods of exposure resulted in a concentration-dependent effect.

3.3. Rotenone Induced a Biphasic Pattern of Neurotoxicity in SH-SY5Y Cells. Exposure of SH-SY5Y cells to ROT $(1 \mu \mathrm{M}$, $10 \mu \mathrm{M}$, and $100 \mu \mathrm{M}$ ) did not result in $\mathrm{LDH}$ release into the medium, at the $24 \mathrm{~h}$ time-point (data not shown). Interestingly, ROT exhibited a biphasic pattern of cellular lyses, at the $48 \mathrm{~h}$ time-point (Figure 3(a)). At this time-point, $1 \mu \mathrm{M}$ ROT led to a significant reduction of $\mathrm{LDH}$ release into the medium, to levels below those of controls. Meanwhile, the $10 \mu \mathrm{M}$ concentration elicited an increase in LDH release, which was significantly higher than that observed for $100 \mu \mathrm{M}$. Thus, cell injury occurred in a concentration-independent manner. After $72 \mathrm{~h}$ exposure there was a concentrationdependent toxicity. Curiously, values for $\mathrm{LDH}$ release at $48 \mathrm{~h}$ and $72 \mathrm{~h}$ for the $10 \mu \mathrm{M}$ concentration were very similar (Figure 3(a)).

Exposure for $24 \mathrm{~h}$ to $10 \mu \mathrm{M}$, and $100 \mu \mathrm{M}$ ROT did not induce mitochondrial dysfunction (Figure 3(b)). After $48 \mathrm{~h}$ exposure there was an increase of mitochondrial dysfunction from $1 \mu \mathrm{M}$ to $10 \mu \mathrm{M}$, in which values were similar to those of the $100 \mu \mathrm{M}$ concentration. However, after $72 \mathrm{~h}$ exposure there 


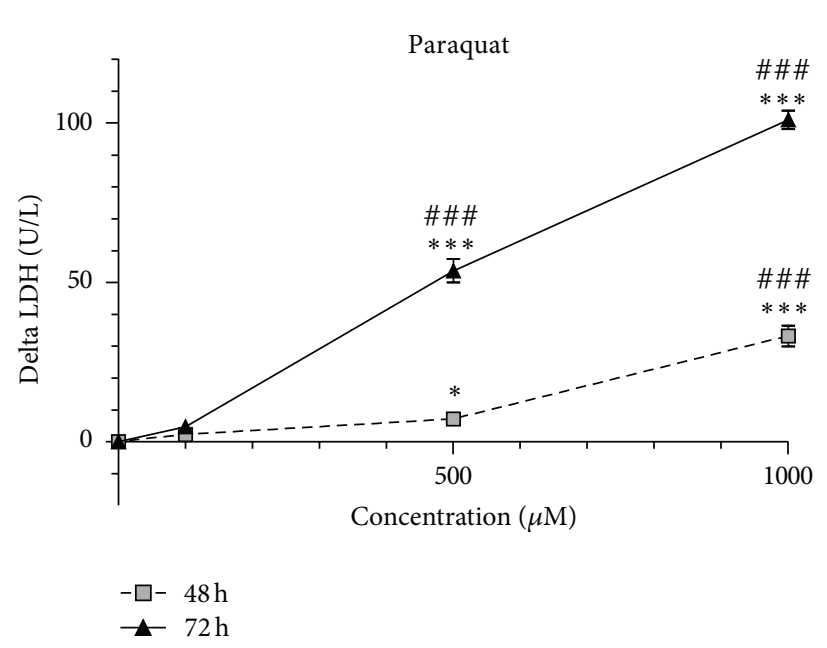

(a)

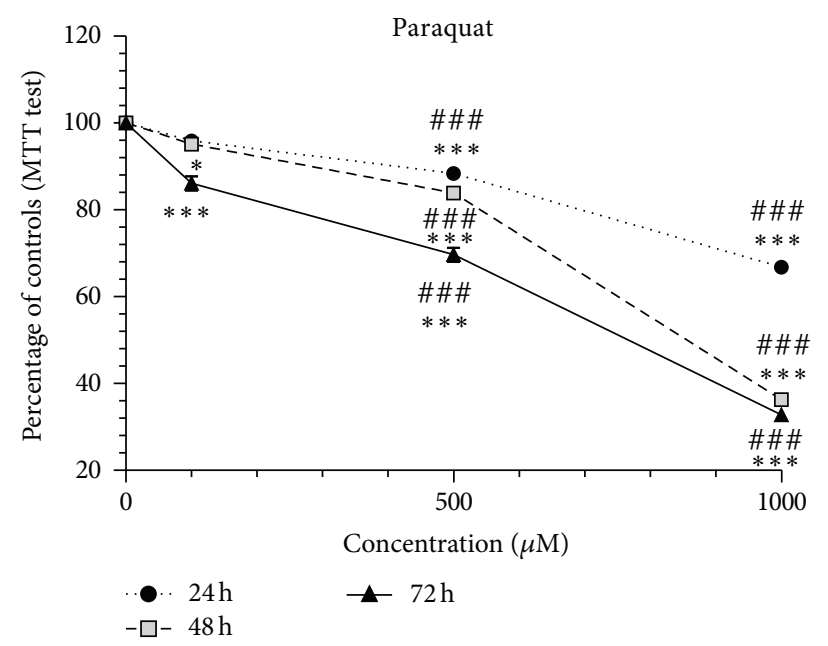

(b)

FIGURE 1: PQ toxicity occurred in a concentration- and time-dependent manner in differentiated SH-SY5Y cells. Cells were incubated with 100,500 and $1000 \mu \mathrm{M}$ of PQ for 24, 48 and $72 \mathrm{~h}$. (a) Increase in LDH release into the medium in differentiated SH-SY5Y cells. The delta increase in LDH release in units per liter (U/L) into the medium was calculated by subtraction of the respective controls (results were pooled from 3 different experiments, each experiment having 6 different culture wells per condition). (b) Mitochondrial dysfunction in differentiated SH-SY5Y cells evaluated by the MTT test. The viability of untreated control cells was set to $100 \%$, and all treatments were expressed as the percentage of the respective controls (results were pooled from 3 different experiments, each experiment having 6 different culture wells per condition). The means were compared using the two-way ANOVA test, followed by the Bonferroni post hoc test $\left({ }^{*} P<0.05\right.$, ${ }^{* * *} P<0.001$ concentration versus control; ${ }^{\# \# \# ~} P<0.001$ concentration versus concentration).

was a concentration-dependent toxicity, with the highest levels of mitochondrial dysfunction attaining values below $50 \%$ at $100 \mu \mathrm{M}$. Comparing the exposure during 24 or $48 \mathrm{~h}$, mostly $10 \mu \mathrm{M}$ and $100 \mu \mathrm{M}$ ROT induced a time-dependent increase in mitochondrial dysfunction (Figure 3(b)).

\subsection{Tiron and Sodium Salicylate Provided Protection against} Paraquat Neurotoxicity. To carry out neuroprotective experiments in human neuroblastoma-differentiated SH-SY5Y cells, we selected the $500 \mu \mathrm{M}$ PQ concentration and the $72 \mathrm{~h}$ exposure period, since under these conditions mitochondrial dysfunction reached about $50 \%$ of controls and cell injury was significant. The cells were preincubated with NAC $(1 \mathrm{mM})$, TIR $(100 \mu \mathrm{M}$ and $1 \mathrm{mM})$, and NaSAL $(100 \mu \mathrm{M}, 1 \mathrm{mM}$, and $10 \mathrm{mM}) 30$ minutes before exposing cells to PQ. Putative protective drugs alone were also tested for their respective toxicities (Figure 4 ).

TIR and NaSAL, both antioxidants, provided partial protection against $500 \mu \mathrm{M}$ PQ neurotoxicity, as revealed by the LDH assay (Figure 4). The protective action of the referred compounds was only detected in cell injury, revealed by the LDH assay, since these compounds did not offer any protection against mitochondrial dysfunction, as revealed by the MTT assay (data not shown). For both TIR and NaSAL, the protective effect was higher at $100 \mu \mathrm{M}$ of both protectors comparatively to the $1 \mathrm{mM}$ concentration (Figure 4). Interestingly, NaSAL alone at the $1 \mathrm{mM}$ concentration showed lower $\mathrm{LDH}$ release than controls, seemingly to reduce cell death occurring in untreated cells (Figure 4).
NAC, an antioxidant and glutathione precursor, did not provide any protection against PQ-induced toxicity as revealed both by LDH and MTT assays (Figure 4).

3.5. GBR 12909, Cycloheximide, and L-NAME Provide Protection against Paraquat Neurotoxicity. GBR $12909(1 \mu \mathrm{M})$, a dopamine transporter blocker, $\mathrm{CHX}(1.8 \mathrm{nM})$, a protein synthesis inhibitor, and L-NAME $(1 \mu \mathrm{M})$, a NOS inhibitor, provided significant protection against PQ neurotoxicity, as revealed by the $\mathrm{LDH}$ assay (Figure 5). $\mathrm{CHX}$ proved to be the most effective. On the other hand, none of the tested drugs proved protection against mitochondrial dysfunction induced by PQ (data not shown).

\section{Discussion}

The key findings of our study conducted in differentiated dopaminergic SH-SY5Y cells were as follows: (1) PQ-induced neurotoxicity was concentration and time dependent, promoting a delayed type of cell death with an early mitochondrial dysfunction; (2) $\mathrm{MPP}^{+}$promoted mitochondrial dysfunction, especially at higher times of exposure, but not cellular lyses; (3) ROT-induced neurotoxicity showed a biphasic pattern promoting a delayed type of cell death at later time-points of exposure and higher concentrations; (4) PQ neurotoxicity could be partially prevented by antioxidants, DAT inhibitors, NOS inhibitors, and protein synthesis inhibitors.

$\mathrm{MPP}^{+}, \mathrm{ROT}$, and PQ are viewed as experimental toxicants to study $\mathrm{PD}$ mechanisms in vitro $[9,30] . \mathrm{MPP}^{+}$and ROT 


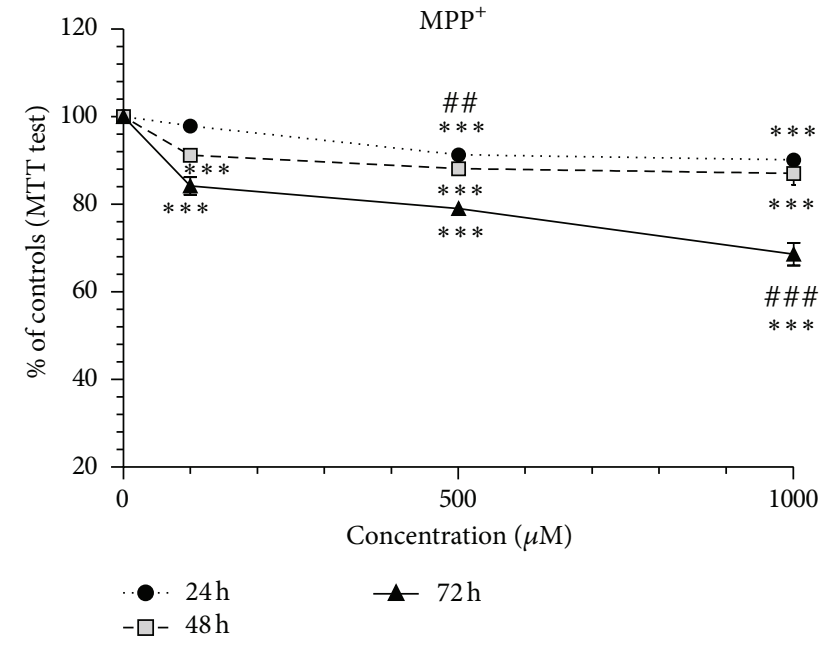

FIGURE 2: $\mathrm{MPP}^{+}$-induced mitochondrial dysfunction in differentiated SH-SY5Y. The cells were incubated with 100, 500, and $1000 \mu \mathrm{M}$ of $\mathrm{MPP}^{+}$, and the MTT test was performed at 24,48 , and $72 \mathrm{~h}$ time-points. Mitochondrial dysfunction in differentiated SH-SY5Y cells evaluated by the MTT test. The viability of untreated control cells was set to $100 \%$, and all treatments were expressed as the percentage of the respective controls (results were pooled from 3 different experiments, each experiment having 6 different culture wells per condition). The means were compared using the twoway ANOVA, followed by the Bonferroni post hoc test $\left(^{* * *} \mathrm{P}<\right.$ 0.001 concentration versus control; ${ }^{\# \#} P<0.01,{ }^{\# \# \# P} P<0.001$ concentration versus concentration).

are commonly used instead of PQ, because of their wellknown mechanisms of toxicity. In addition, studies using $\mathrm{MPP}^{+}$and ROT have already given significant insights into the molecular mechanisms of dopaminergic neuronal death $[24,31]$. However, there is a need for more reliable cultured cell models of PD. Several studies using SH-SY5Y cells with these neurotoxicants have been published, without ever having fully elucidated their differential effects, concerning to cell death and optimal concentrations. In the present study, we compared the neurotoxicity of PQ with that of ROT and $\mathrm{MPP}^{+}$using differentiated dopaminergic SH-SY5Y cells. Our data demonstrated that $\mathrm{PQ}$ toxicity involved mitochondrial dysfunction and cell death. The increase in LDH release and mitochondrial dysfunction after PQ exposure occurred in a concentration and time dependent manner and was more pronounced at late times of exposure. We verified the existence of two events, an earlier damage to the mitochondrial electronic transport chain that may precede a later membrane burst, typical of cellular lyses. This cellular membrane disruption may be also promoted by external aggressions or other unknown mechanisms promoted by PQ. Our results are in accordance with our analysis, since mitochondrial dysfunction occurred at $24 \mathrm{~h}$ and $\mathrm{LDH}$ was not measurable at this time point. At higher PQ concentrations and times of exposure, once cells are not intact, the mitochondrial chain is not functional, thus leading to low MTT metabolism.

When compared to $\mathrm{MPP}^{+}$, $\mathrm{PQ}$ induced a more pronounced mitochondrial dysfunction and cell injury for the same concentrations and time of exposure. Mitochondrial dysfunction may corroborate the hypothesis that $\mathrm{PQ}$, like $\mathrm{MPP}^{+}$, inhibits the complex I of the mitochondrial chain $[6,23]$. Our study showed that in the same concentration range (100 to $1000 \mu \mathrm{M}) \mathrm{PQ}$, but not $\mathrm{MPP}^{+}$, induced cell lyses and LDH release. This event occurred several hours after mitochondrial dysfunction, since LDH release became only evident after $48 \mathrm{~h}$ exposure. In fact, $\mathrm{MPP}^{+}$exposed cells might have lost their metabolic capacity but yet not their membrane integrity, suggesting delayed cell death. Not only SH-SY5Ydifferentiated cells seem to be more susceptible to PQ but also PQ is more stable in solution than $\mathrm{MPP}^{+}$, which is photosensitive and may lose activity when in solution with longer exposure periods. Therefore, PQ may represent several advantages over $\mathrm{MPP}^{+}$to study Parkinson's mechanisms in vitro, namely, when using cultured cells.

Concerning ROT, a widely used toxicant to promote dopaminergic toxicity, it showed a biphasic pattern of neurotoxicity. Our results are not in agreement with those presented by Molina-Jimenez [19], who observed that ROT caused a proportional time- and dose-dependent decrease in SH-SY5Y cellular viability. This can be explained by a different cell culture protocol, namely, their FBS removal and lower cellular density. Herein, ROT, at $1 \mu \mathrm{M}$ for $48 \mathrm{~h}$, reduced cell lyses and promoted lower LDH leakage compared to control cells, an effect no longer seen at latter times of exposure. On the other hand, the MTT assay proved mitochondrial dysfunction after $48 \mathrm{~h}$ exposure to $1 \mu \mathrm{M}$. This may be connected to a late death pattern, as ROT is postulated to be a high affinity complex I inhibitor [7] and to induce apoptosis via activation of caspase 3 apoptosis pathway [20]. In fact, ROT binds near to the quinone-binding site and blocks electron transport, preventing NADH from being converted to ATP; in this way the proton pumping is compromised, which culminates in increased superoxide generation, and consequent cell death [32]. Cell membrane rupture occurs several hours after compromising the metabolic activity at lower concentrations, though at higher concentrations it may demonstrate toxicity by other means [8]. Other studies showed that ROT causes apoptosis at low doses and necrosis when applied at high doses, thus corroborating our results [33]. We demonstrated in SH-SY5Y cells that PQ promoted a more defined pattern of time-concentration-dependent cell death; meanwhile, ROT induced a biphasic pattern of toxicity. Moreover, PQ chloride salt is water soluble, while ROT has to be prepared in DMSO, which is an hazardous substance. Therefore, PQ may represent advantages over ROT to study Parkinson's mechanisms in vitro, at least in SH-SY5Ydifferentiated cells.

Comparing the toxicity of ROT and $\mathrm{MPP}^{+}$in SH-SY5Ydifferentiated cells, one can conclude that ROT promoted a higher grade of mitochondrial dysfunction and cell injury than $\mathrm{MPP}^{+}$. In fact, 10 times lower concentrations of ROT and shorter exposure times were required for achieving the degree of toxicity seen with $\mathrm{MPP}^{+}$. One possible explanation may be that ROT does not need a transporter to enter the cells as it crosses membranes by diffusion [7]. Our results are in accordance with Richardson and collaborators who demonstrated that higher $\mathrm{MPP}^{+}$concentrations 


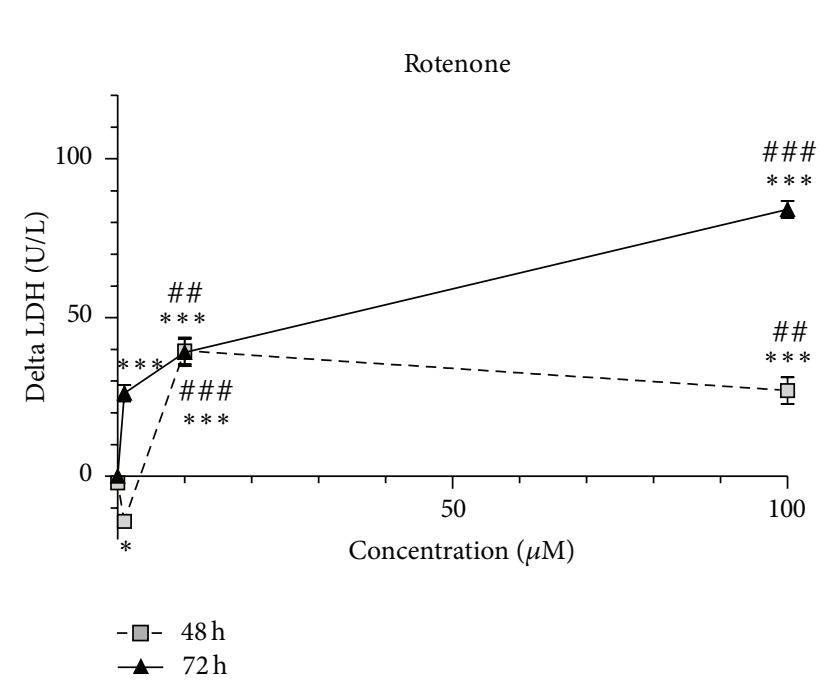

(a)

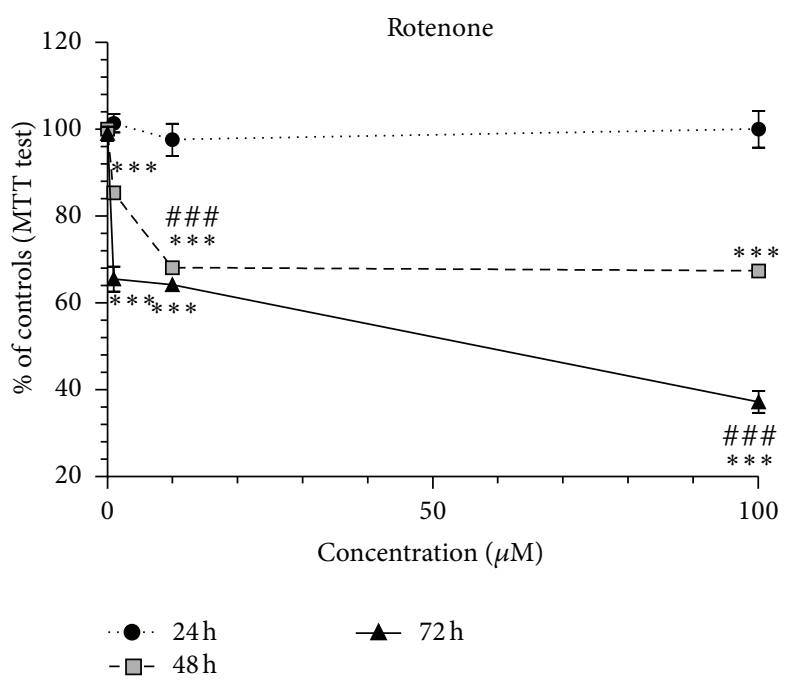

(b)

FIGURE 3: ROT-induced neurotoxicity showed a biphasic pattern with mitochondrial dysfunction and cell death in differentiated SH-SY5Y cells. The cells were incubated with 1,10 , and $100 \mu \mathrm{M}$ of ROT, and then MTT and LDH tests were performed at 24, 48, and 72 h time points. (a) Increase in LDH release in units per liter (U/L) into the medium in differentiated SH-SY5Y cells. The delta increase in LDH release into the medium was calculated by subtraction of the respective controls (results were pooled from 3 different experiments, each experiment having 6 different culture wells per condition). (b) Mitochondrial dysfunction in differentiated SH-SY5Y cells evaluated by the MTT test. The viability of untreated control cells was set to $100 \%$, and all treatments were expressed as the percentage of the respective controls (results were pooled from 3 different experiments, each experiment having 6 different culture wells per condition). The means were compared using the two-way ANOVA, followed by the Bonferroni post hoc test $\left({ }^{* * *} P<0.001\right.$ concentration versus control; ${ }^{\# *} P<0.01$, ${ }^{\# \#} P<0.001$ concentration versus concentration).

were required to achieve the same degree of complex I inhibition, showing that ROT has a higher complex I affinity [8]. In contrast to ROT, the concentrations of $\mathrm{MPP}^{+}$used in our SH-SY5Y-differentiated cells did not result in cell lyses during the $72 \mathrm{~h}$ of exposure. Other studies using $\mathrm{SH}-$ SY5Y have reported cell death using higher concentrations of $\mathrm{MPP}^{+}$, up to $10 \mathrm{mM}[22,34,35]$. Moreover, differentiated SHSY5Y cells have an enhanced resistance towards neurotoxins. Our group recently showed that differentiation of SH-SY5Y cells with RA and TPA led to SH-SY5Y neurons with higher ability to accumulate dopamine and higher resistance towards dopamine neurotoxicity [18]. Importantly, a study by Cheung and coauthors demonstrated that differentiation of SH-SY5Y cells with RA conferred higher resistance towards $\mathrm{MPP}^{+}$toxicity [36]. Thus, using higher concentrations of $\mathrm{MPP}^{+}$and longer periods of exposure should be necessary to obtain significant cell lyses.

Our study demonstrated that several compounds could partially prevent or slow PQ-induced toxicity. NaSAL is known to prevent PQ-induced apoptosis in the rat lung [37]. In fact, one of the proposed mechanisms of PQ neurotoxicity is oxidative stress by producing ROS such as superoxide anion $\left(\mathrm{O}_{2}{ }^{-}\right)$, hydroxyl radicals $\left(\mathrm{OH}^{*}\right)$, and hydrogen peroxide $\left(\mathrm{H}_{2} \mathrm{O}_{2}\right)$, which increase lipid peroxidation, increase oxidation of proteins, DNA and iron content and promote a marked decrease in reduced glutathione (GSH) and GSH/glutathione disulfide ratio $[23,38]$. Oxidative stress is also a typical feature of PD brains [39]. Salicylates are important HO* scavengers and therefore reduce PQ toxicity [37]. On the other hand, salicylates may also form stable complexes with PQ [40]. These two proposed mechanisms may be the explanation of the neuroprotection obtained by us with NaSAL against PQinduced injury. Interestingly, NaSAL did not prevent mitochondrial dysfunction. On the other hand, LDH values were reduced, possibly because direct cellular membrane damage was prevented, either by complex forming or oxidative radical reduction. Still PQ may promote toxicity by other means, once neurotoxicity was not fully prevented.

Another antioxidant used, TIR, partially prevented PQinduced neurotoxicity. TIR is a known scavenger of $\mathrm{O}_{2}{ }^{-}$, acting both at extracellular and intracellular levels. $\mathrm{O}_{2}{ }^{-{ }^{-}}$that originated from PQ redox cycle can be scavenged by TIR, therefore affording protection. Also, $\mathrm{O}_{2}{ }^{\cdot-}$ can be converted further to $\mathrm{H}_{2} \mathrm{O}_{2}$ and to $\mathrm{HO}^{\bullet}$ through Fenton-type reactions, using $\mathrm{Fe}^{2+}$, promoting more oxidative stress [41]. However, TIR only partially prevented cell lyses and not mitochondrial dysfunction promoted by $\mathrm{PQ}$, which may indicate that its neurotoxicity occurred by additional mechanisms.

PQ-induced cell death might occur through the formation of reactive nitrogen species (RNS), which also promote oxidative stress. The NOS inhibitor L-NAME also attenuated PQ toxicity. Nitric oxide produced by NOS forms peroxynitrite anion, by reacting with $\mathrm{O}_{2}{ }^{--}$produced in the redox-cycle of $\mathrm{PQ}$, crosses membranes, and can easily oxidize proteins, lipids, RNA, and DNA [42]. Overall the protective effects of the two antioxidants and the NO synthesis inhibitor corroborate the hypothesis that oxidative stress is a major mechanism of PQ neurotoxicity [23, 42, 43]. 


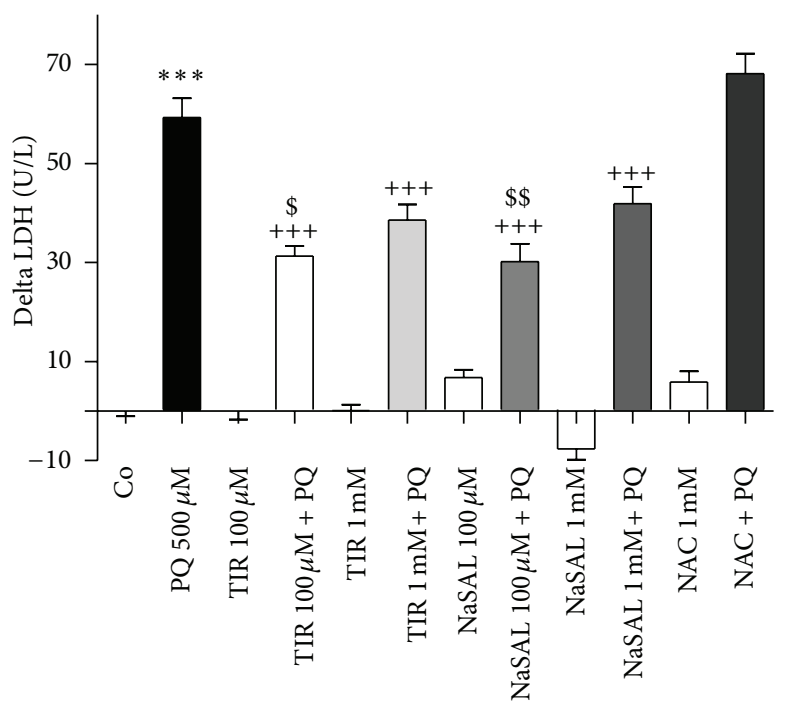

FIGURE 4: TIR and NaSAL decreased PQ-induced LDH release into the medium, while NAC afforded no protection. Differentiated SHSY5Y cells were pretreated with TIR $(100 \mu \mathrm{M}$ and $1 \mathrm{mM}), \mathrm{NaSAL}$ $(100 \mu \mathrm{M}, 1 \mathrm{mM})$, and NAC $(1 \mathrm{mM}) 30$ minutes prior to cultures exposure to PQ for $72 \mathrm{~h}$. The delta increase in $\mathrm{LDH}$ release in units per liter $(\mathrm{U} / \mathrm{L})$ into the medium was calculated by subtraction of the respective controls (results were pooled from 3 different experiments, each experiment having 6 different culture wells per condition). The means were compared using one-way ANOVA, followed by Student-Newman-Keuls post hoc test $\left({ }^{* * *} P<0.001 \mathrm{PQ}\right.$ versus control; ${ }^{+++} P<0.001 \mathrm{PQ}$ versus $\mathrm{PQ}$ plus protector; ${ }^{\$} P<0.05$, ${ }^{\$} P<0.01 \mathrm{PQ}$ plus protector low concentration versus PQ plus protector high concentration).

Our study revealed that $\mathrm{CHX}$, a protein synthesis inhibitor, protected against PQ-induced neurotoxicity. Therefore, PQ-induced cell death might involve proteins, whose synthesis is prevented by CHX. Protein synthesis is involved in many processes of programmed and nonprogrammed cell death, and therefore PQ-induced dopaminergic death might involve those processes [44].

GBR 12909 conferred partial protection against PQinduced neurotoxicity revealing that PQ entrance into the dopaminergic neuron might occur through the DAT transporter, which is corroborated by Yang and Tiffany-Castiglioni [23]. Since PQ is structurally very similar to $\mathrm{MPP}^{+}$, it may as well use dopamine transporters [45], though this still remains a controversial issue, as there are contrary opinions like that of Richardson and collaborators [8], who claim that PQ toxicity is independent of DAT expression or Ramachandiran and coauthors [46], who claim that PQ does not require a functional dopamine transporter for dopaminergic toxicity. In fact, we found that despite DAT blocking, PQ still exerts neurotoxicity, so it is suggested that it may nevertheless enter the cell or exert toxic effects on the outside leading to cellular lyses.

Other studies have evaluated the effects of the pharmacological agents that we used against PQ neurotoxicity to circumvent $\mathrm{MPP}^{+}$or ROT neurotoxicity. L-NAME did not present any significant protection to $\mathrm{MPP}^{+}$toxicity in

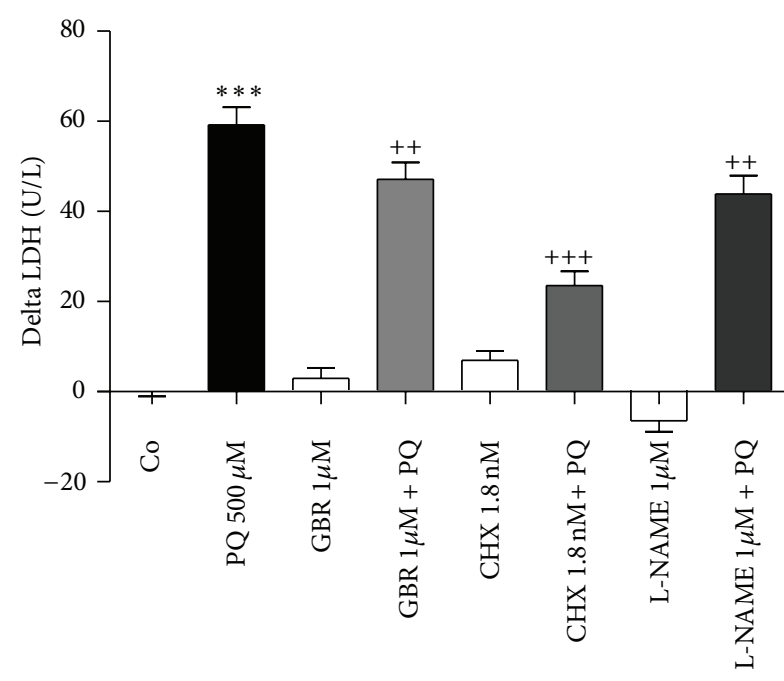

Figure 5: CHX, GBR 12909, and L-NAME decreased PQ-induced LDH release into the medium. Differentiated SH-SY5Y cells were pretreated with GBR $12909(1 \mu \mathrm{M}), \mathrm{CHX}(1,8 \mathrm{nM})$, and L-NAME $(1 \mu \mathrm{M}) 30$ minutes prior to cultures exposure to PQ for $72 \mathrm{~h}$. The delta increase in $\mathrm{LDH}$ release in units per liter $(\mathrm{U} / \mathrm{L})$ into the medium was calculated by subtraction of the respective controls (results were pooled from 3 different experiments, each experiment having 6 different culture wells per condition). The means were compared using one-way ANOVA, followed by Student-NewmanKeuls post hoc test $\left({ }^{* * *} P<0.001 \mathrm{PQ}\right.$ versus control; ${ }^{++} P<0.01$, ${ }^{+++} P<0.001 \mathrm{PQ}$ versus $\mathrm{PQ}$ plus protector).

SH-SY5Y cells [47], whereas GBR 12909 blocked its neurotoxic effects [17]. Meanwhile, CHX reduced proapoptotic proteins production in response to $\mathrm{MPP}^{+}$-induced toxicity [48], and also $\mathrm{CHX}$ blocked $\mathrm{MPP}^{+}$-induced cell death in the dopaminergic cell line MN9D [49]. In rats, NaSAL significantly attenuated striatal dopamine depletion caused by intrastriatal $\mathrm{MPP}^{+}$infusion [50]. In what concerns ROT, CHX was demonstrated to reduce cell death in cultured cortical neurons [51]. In another study, GBR 12909 significantly prevented the ROT-induced decrease of cell viability in PC12 cells [52]. In rats, NaSAL demonstrated neuroprotective efficacy against ROT toxicity [53]. Also, in oral cancer cell lines ROT-induced apoptosis was inhibited by TIR [54].

\section{Conclusions}

The results obtained in the present study showed that PQ promoted a diverse profile of toxicity when compared to $\mathrm{MPP}^{+}$and ROT and could present advantages over those two toxicants for modelling PD in vitro. In fact, $\mathrm{PQ}$ in differentiated dopaminergic SH-SY5Y cells promoted a concentrationand time-dependent toxicity, promoting a delayed type of cell death with mitochondrial dysfunction leading to cellular lyses. We further studied the mechanisms of PQ-induced toxicity and demonstrated that antioxidants, NOS inhibitors, DAT inhibitors, and protein synthesis inhibitors could be useful tools in preventing dopaminergic toxicity, at least in vitro. 
Abbreviations

$\begin{array}{ll}\text { CHX: } & \text { Cycloheximide } \\ \text { DAT: } & \text { Dopamine transporter } \\ \text { D-MEM: } & \text { Dulbecco's Modified Eagle Media } \\ \text { DMSO: } & \text { Dimethyl sulfoxide } \\ \text { GBR 12909: } & \text { 1-(2-[Bis(4-fluorophenyl)methoxy]ethyl)-4- } \\ & \text { (3-phenyl-propyl)piperazine } \\ \text { GSH: } & \text { Reduced glutathione } \\ \mathrm{H}_{2} \mathrm{O}_{2}: & \text { Hydrogen peroxide } \\ \text { LDH: } & \text { Lactate dehydrogenase } \\ \text { L-NAME: } & \text { N } \text {-Nitro-L-arginine methyl ester }^{-} \\ \text {MPP }{ }^{+}: & \text {hydrochloride } \\ \text { MPPP: } & \text { 1-Methyl-4-phenyl-pyridinium ion } \\ \text { MPTP: } & \text { 1-Methyl-4-phenyl-1,2,3,6- } \\ & \text { tetrahydropyridine } \\ \text { MTT: } & \text { 3-[4,5-Dimethylthiazol]-2,5-diphenyltetra- } \\ & \text { zolium } \\ \text { NAC: } & \text { N-Acetylcysteine } \\ \text { NADH: } & \text { Nicotinamide adenine dinucleotide reduced } \\ & \text { form } \\ \text { NaSAL: } & \text { 2-Hydroxybenzoic acid sodium salt } \\ \text { NEAA: } & \text { Nonessential amino acids } \\ \text { NOS: } & \text { Nitric oxide synthase } \\ \mathrm{O}_{2}{ }^{--}: & \text {Superoxide anion } \\ \text { OH }: & \text { Hydroxyl radical } \\ \text { PBS: } & \text { Phosphate-buffered saline } \\ \text { PD: } & \text { Parkinson's disease } \\ \text { PQ: } & \text { Paraquat } \\ \text { RA: } & \text { Retinoic acid } \\ \text { RNS: } & \text { Reactive nitrogen species } \\ \text { ROS: } & \text { Reactive oxygen species } \\ \text { ROT: } & \text { Rotenone } \\ \text { SDS: } & \text { Sodium dodecyl sulfate } \\ \text { SNpc: } & \text { Substantia nigra pars compacta } \\ \text { TIR: } & \text { Tiron } \\ \text { TPA: } & \text { 12-O-Tetradecanoyl-phorbol-13-acetate. } \\ & \end{array}$

\section{Conflict of Interests}

The authors declare no conflict of interests.

\section{Acknowledgments}

This work received financial support from "Fundacão para a Ciência e Tecnologia," Portugal (Project PTDC/SAU-FCF/ 102958/2008), under the frame of "Programa Operacional Temático Factores de Competitividade (COMPTE) do Quadro Comunitário de Apoio III" and "Fundo Comunitário Europeu (FEDER) (FCOMP-01-0124-FEDER-011079).” J. P. Capela was the recipient of a Postdoc grant from "Fundação para a Ciência e a Tecnologia," Portugal (SFRH/BPD/ 30776/2006).

\section{References}

[1] L. M. de Lau and M. M. Breteler, "Epidemiology of Parkinson's disease," The Lancet Neurology, vol. 5, no. 6, pp. 525-535, 2006.
[2] P. Piccini, D. J. Burn, R. Ceravolo, D. Maraganore, and D. J. Brooks, "The role of inheritance in sporadic Parkinson's disease: evidence from a longitudinal study of dopaminergic function in twins," Annals of Neurology, vol. 45, no. 5, pp. 577-582, 1999.

[3] R. Betarbet, T. B. Sherer, G. MacKenzie, M. Garcia-Osuna, A. V. Panov, and J. T. Greenamyre, "Chronic systemic pesticide exposure reproduces features of Parkinson's disease," Nature Neuroscience, vol. 3, no. 12, pp. 1301-1306, 2000.

[4] J. W. Langston and P. A. Ballard Jr., "Parkinson's disease in a chemist working with 1-methyl-4-phenyl-1,2,5,6tetrahydropyridine," The New England Journal of Medicine, vol. 309, no. 5, article 310, 1983.

[5] R. J. Smeyne and V. Jackson-Lewis, "The MPTP model of Parkinson's disease," Molecular Brain Research, vol. 134, no. 1, pp. 57-66, 2005.

[6] K. Suzuki, Y. Mizuno, and M. Yoshida, "Effects of 1-methyl-4phenyl-1,2,3,6-tetrahydropyridine (MPTP)-like compounds on mitochondrial respiration," Advances in Neurology, vol. 53, pp. 215-218, 1990.

[7] J. T. Greenamyre, R. Betarbet, and T. B. Sherer, "The rotenone model of Parkinson's disease: genes, environment and mitochondria," Parkinsonism and Related Disorders, vol. 9, supplement 2, pp. S59-S64, 2003.

[8] J. R. Richardson, Y. Quan, T. B. Sherer, J. T. Greenamyre, and G. W. Miller, "Paraquat neurotoxicity is distinct from that of MPTP and rotenone," Toxicological Sciences, vol. 88, no. 1, pp. 193-201, 2005.

[9] J. Bové, D. Prou, C. Perier, and S. Przedborski, “Toxin-induced models of Parkinson's disease," NeuroRx, vol. 2, no. 3, pp. 484494, 2005.

[10] J. M. Gorell, C. C. Johnson, B. A. Rybicki, E. L. Peterson, and R. J. Richardson, "The risk of Parkinson's disease with exposure to pesticides, farming, well water, and rural living," Neurology, vol. 50, no. 5, pp. 1346-1350, 1998.

[11] J. T. Hughes, "Brain damage due to Paraquat poisoning: a fatal case with neuropathological examination of the brain," NeuroToxicology, vol. 9, no. 2, pp. 243-248, 1988.

[12] M. J. Kang, S. J. Gil, and H. C. Koh, "Paraquat induces alternation of the dopamine catabolic pathways and glutathione levels in the substantia nigra of mice," Toxicology Letters, vol. 188, no. 2, pp. 148-152, 2009.

[13] A. L. McCormack, M. Thiruchelvam, A. B. Manning-Bog et al., "Environmental risk factors and Parkinson's disease: selective degeneration of nigral dopaminergic neurons caused by the herbicide paraquat," Neurobiology of Disease, vol. 10, no. 2, pp. 119-127, 2002.

[14] K. Shimizu, K. Matsubara, K. Ohtaki, S. Fujimaru, O. Saito, and H. Shiono, "Paraquat induces long-lasting dopamine overflow through the excitotoxic pathway in the striatum of freely moving rats," Brain Research, vol. 976, no. 2, pp. 243-252, 2003.

[15] T. Tawara, T. Fukushima, N. Hojo et al., "Effects of paraquat on mitochondrial electron transport system and catecholamine contents in rat brain," Archives of Toxicology, vol. 70, no. 9, pp. 585-589, 1996.

[16] D. Bagchi, M. Bagchi, E. A. Hassoun, and S. J. Stohs, "In vitro and in vivo generation of reactive oxygen species, DNA damage and lactate dehydrogenase leakage by selected pesticides," Toxicology, vol. 104, no. 1-3, pp. 129-140, 1995.

[17] S. P. Presgraves, T. Ahmed, S. Borwege, and J. N. Joyce, “Terminally differentiated SH-SY5Y cells provide a model system for studying neuroprotective effects of dopamine agonists," Neurotoxicity Research, vol. 5, no. 8, pp. 579-598, 2003. 
[18] P. S. Ferreira, T. B. Nogueira, V. M. Costa et al., "Neurotoxicity of "ecstasy" and its metabolites in human dopaminergic differentiated SH-SY5Y cells," Toxicology Letters, vol. 216, no. 2-3, pp. 159-170, 2013.

[19] M. F. Molina-Jimenez, M. I. Sanchez-Reus, and J. Benedi, “Effect of fraxetin and myricetin on rotenone-induced cytotoxicity in SH-SY5Y cells: comparison with $\mathrm{N}$-acetylcysteine," European Journal of Pharmacology, vol. 472, no. 1-2, pp. 81-87, 2003.

[20] T. Pan, P. Rawal, Y. Wu, W. Xie, J. Jankovic, and W. Le, "Rapamycin protects against rotenone-induced apoptosis through autophagy induction," Neuroscience, vol. 164, no. 2, pp. 541-551, 2009.

[21] K. Y. Chau, L. V. P. Korlipara, J. M. Cooper, and A. H. V. Schapira, "Protection against paraquat and A53T alphasynuclein toxicity by cabergoline is partially mediated by dopamine receptors," Journal of the Neurological Sciences, vol. 278, no. 1-2, pp. 44-53, 2009.

[22] J. R. Mathiasen, B. A. W. McKenna, M. S. Saporito et al., "Inhibition of mixed lineage kinase 3 attenuates $\mathrm{MPP}^{+}$-induced neurotoxicity in SH-SY5Y cells," Brain Research, vol. 1003, no. 1-2, pp. 86-97, 2004.

[23] W. Yang and E. Tiffany-Castiglioni, "The bipyridyl herbicide paraquat produces oxidative stress-mediated toxicity in human neuroblastoma SH-SY5Y cells: relevance to the dopaminergic pathogenesis," Journal of Toxicology and Environmental Health-Part A, vol. 68, no. 22, pp. 1939-1961, 2005.

[24] H. An, I. S. Kim, S. Koppula et al., "Protective effects of Gastrodia elata Blume on $\mathrm{MPP}^{+}$-induced cytotoxicity in human dopaminergic SH-SY5Y cells," Journal of Ethnopharmacology, vol. 130, no. 2, pp. 290-298, 2010.

[25] J. P. Capela, C. Macedo, P. S. Branco et al., "Neurotoxicity mechanisms of thioether ecstasy metabolites," Neuroscience, vol. 146, no. 4, pp. 1743-1757, 2007.

[26] J. Yamada, S. Yoshimura, H. Yamakawa et al., "Cell permeable ROS scavengers, Tiron and Tempol, rescue PC12 cell death caused by pyrogallol or hypoxia/reoxygenation," Neuroscience Research, vol. 45, no. 1, pp. 1-8, 2003.

[27] M. A. Lopes, A. Meisel, U. Dirnagl, F. D. Carvalho, and M. D. L. Bastos, "Doxorubicin induces biphasic neurotoxicity to rat cortical neurons," NeuroToxicology, vol. 29, no. 2, pp. 286-293, 2008.

[28] J. T. Bau and E. U. Kurz, "Sodium salicylate is a novel catalytic inhibitor of human DNA topoisomerase II alpha," Biochemical Pharmacology, vol. 81, no. 3, pp. 345-354, 2011.

[29] J. P. Capela, K. Ruscher, M. Lautenschlager et al., "Ecstasyinduced cell death in cortical neuronal cultures is serotonin 2A-receptor-dependent and potentiated under hyperthermia," Neuroscience, vol. 139, no. 3, pp. 1069-1081, 2006.

[30] K. Nakamura, D. Tsuchiya, M. Inden, and T. Taniguchi, "In vitro neurodegeneration model: dopaminergic toxin-induced apoptosis in human SH-SY5Y cells," International Congress Series, vol. 1260, pp. 287-290, 2004.

[31] D. V. G. De Andrade, D. Madureira de Oliveria, G. Barreto et al., "Effects of the extract of Anemopaegma mirandum (Catuaba) on Rotenone-induced apoptosis in human neuroblastomas SHSY5Y cells," Brain Research, vol. 1198, pp. 188-196, 2008.

[32] A. J. Lambert and M. D. Brand, "Inhibitors of the quinonebinding site allow rapid superoxide production from mitochondrial NADH:ubiquinone oxidoreductase (complex I)," The Journal of Biological Chemistry, vol. 279, no. 38, pp. 3941439420, 2004.
[33] A. Hartley, J. M. Stone, C. Heron, J. M. Cooper, and A. H. V. Schapira, "Complex I inhibitors induce dose-dependent apoptosis in PC12 cells: relevance to Parkinson's disease," Journal of Neurochemistry, vol. 63, no. 5, pp. 1987-1990, 1994.

[34] K. E. Beck, L. A. De Girolamo, M. Griffin, and E. E. Billett, “The role of tissue transglutaminase in 1-methyl-4-phenylpyridinium $\left(\mathrm{MPP}^{+}\right)$-induced toxicity in differentiated human SH-SY5Y neuroblastoma cells," Neuroscience Letters, vol. 405, no. 1-2, pp. 46-51, 2006.

[35] C. P. Fall and J. P. Bennett, "Characterization and time course of $\mathrm{MPP}^{+}$-induced apoptosis in human SH-SY5Y neuroblastoma cells," Journal of Neuroscience Research, vol. 55, no. 5, pp. 620628, 1999.

[36] Y. T. Cheung, W. K. W. Lau, M. S. Yu et al., "Effects of all-transretinoic acid on human SH-SY5Y neuroblastoma as in vitro model in neurotoxicity research," NeuroToxicology, vol. 30, no. 1, pp. 127-135, 2009.

[37] R. J. Dinis-Oliveira, C. Sousa, F. Remião et al., "Sodium salicylate prevents paraquat-induced apoptosis in the rat lung," Free Radical Biology and Medicine, vol. 43, no. 1, pp. 48-61, 2007.

[38] M. P. Mattson, "Neuronal life-and-death signaling, apoptosis, and neurodegenerative disorders," Antioxidants and Redox Signaling, vol. 8, no. 11-12, pp. 1997-2006, 2006.

[39] P. Jenner, "Oxidative stress as a cause of Parkinson's disease," Acta Neurologica Scandinavica, Supplement, vol. 84, no. 136, pp. 6-15, 1991.

[40] R. J. Dinis-Oliveira, P. G. de Pinho, A. C. S. Ferreira et al., "Reactivity of paraquat with sodium salicylate: formation of stable complexes," Toxicology, vol. 249, no. 2-3, pp. 130-139, 2008.

[41] R. Franco, S. Li, H. Rodriguez-Rocha, M. Burns, and M. I. Panayiotidis, "Molecular mechanisms of pesticide-induced neurotoxicity: relevance to Parkinson's disease," ChemicoBiological Interactions, vol. 188, no. 2, pp. 289-300, 2010.

[42] M. J. La Voie and T. G. Hastings, "Peroxynitrite- and nitriteinduced oxidation of dopamine: implications for nitric oxide in dopaminergic cell loss," Journal of Neurochemistry, vol. 73, no. 6, pp. 2546-2554, 1999.

[43] W. L. Yang and A. Y. Sun, "Paraquat-induced free radical reaction in mouse brain microsomes," Neurochemical Research, vol. 23, no. 1, pp. 47-53, 1998.

[44] C. Harms, M. Lautenschlager, A. Bergk et al., "Differential mechanisms of neuroprotection by $17 \beta$-estradiol in apoptotic versus necrotic neurodegeneration," Journal of Neuroscience, vol. 21, no. 8, pp. 2600-2609, 2001.

[45] B. K. Barlow, M. J. Thiruchelvam, L. Bennice, D. A. CorySlechta, N. Ballatori, and E. K. Richfield, "Increased synaptosomal dopamine content and brain concentration of paraquat produced by selective dithiocarbamates," Journal of Neurochemistry, vol. 85, no. 4, pp. 1075-1086, 2003.

[46] S. Ramachandiran, J. M. Hansen, D. P. Jones, J. R. Richardson, and G. W. Miller, "Divergent mechanisms of paraquat, $\mathrm{MPP}^{+}$, and rotenone toxicity: oxidation of thioredoxin and caspase3 activation," Toxicological Sciences, vol. 95, no. 1, pp. 163-171, 2007.

[47] H. S. Lee, C. W. Park, and Y. S. Kim, "MPP' increases the vulnerability to oxidative stress rather than directly mediating oxidative damage in human neuroblastoma cells," Experimental Neurology, vol. 165, no. 1, pp. 164-171, 2000.

[48] J. Dennis and J. P. Bennett, "Interactions among nitric oxide and Bcl-family proteins after $\mathrm{MPP}^{+}$exposure of SH-SY5Y neural 
cells II: exogenous NO replicates $\mathrm{MPP}^{+}$actions," Journal of Neuroscience Research, vol. 72, no. 1, pp. 89-97, 2003.

[49] W. S. Choi, L. M. T. Canzoniero, S. L. Sensi et al., "Characterization of $\mathrm{MPP}^{+}$-induced cell death in a dopaminergic neuronal cell line: role of macromolecule synthesis, cytosolic calcium, caspase, and Bcl-2-related proteins," Experimental Neurology, vol. 159, no. 1, pp. 274-282, 1999.

[50] K. Sairam, K. S. Saravanan, R. Banerjee, and K. P. Mohanakumar, "Non-steroidal anti-inflammatory drug sodium salicylate, but not diclofenac or celecoxib, protects against 1-methyl4-phenyl pyridinium-induced dopaminergic neurotoxicity in rats," Brain Research, vol. 966, no. 2, pp. 245-252, 2003.

[51] W. Pei, A. K. Liou, and J. Chen, "Two caspase-mediated apoptotic pathways induced by rotenone toxicity in cortical neuronal cells," The FASEB Journal, vol. 17, no. 3, pp. 520-522, 2003.

[52] Y. Sai, Q. Wu, W. Le, F. Ye, Y. Li, and Z. Dong, "Rotenoneinduced PC12 cell toxicity is caused by oxidative stress resulting from altered dopamine metabolism," Toxicology in Vitro, vol. 22, no. 6, pp. 1461-1468, 2008.

[53] P. Thakur and B. Nehru, "Anti-inflammatory properties rather than anti-oxidant capability is the major mechanism of neuroprotection by sodium salicylate in a chronic rotenone model of Parkinson's disease," Neuroscience, vol. 231, pp. 420-431, 2013.

[54] J. Lee, M. S. Huang, I. C. Yang et al., "Essential roles of caspases and their upstream regulators in rotenone-induced apoptosis," Biochemical and Biophysical Research Communications, vol. 371, no. 1, pp. 33-38, 2008. 

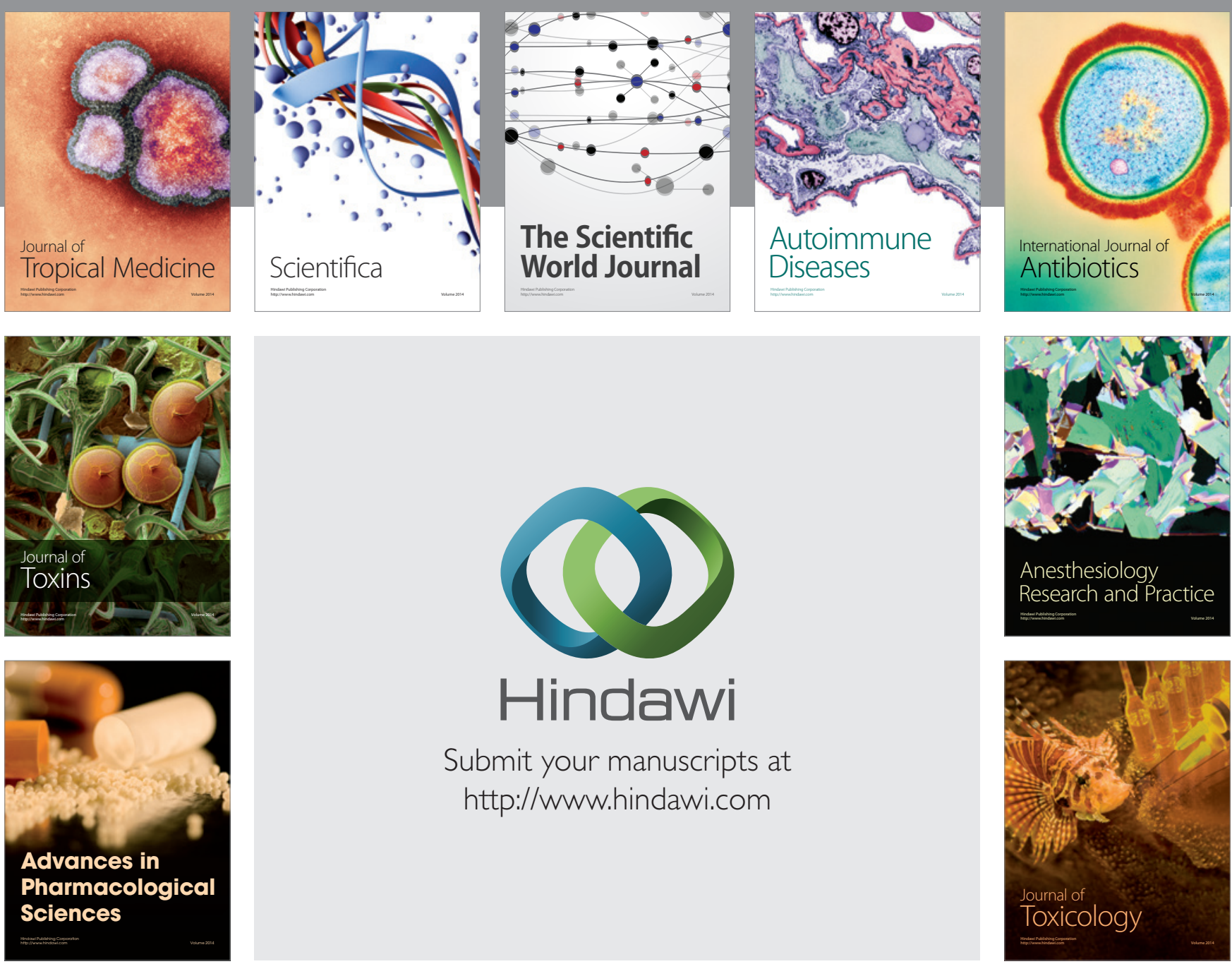

\section{Hindawi}

Submit your manuscripts at

http://www.hindawi.com
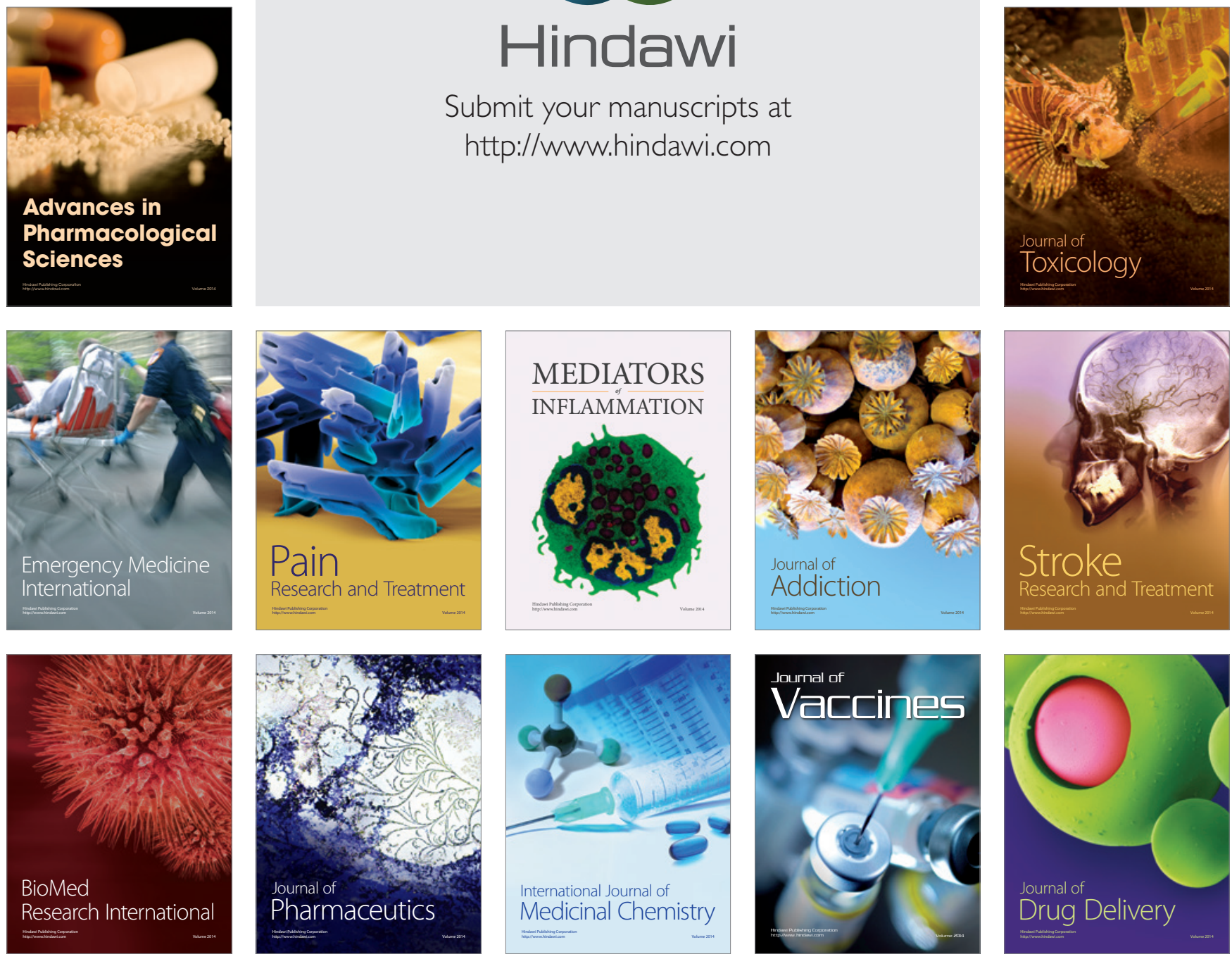